genden Arbeit Ende 1984 wieder manches geändert hat, verhilft eine solche Publikation zu einem ausgewogenen Urteil.

Hans Jolowicz

\title{
Karin Bollmann
}

\section{Massenmedien und Nachrichtengebung in Mexiko}

Eine empirische Analyse zum Spannungsverhältnis von staatlicher, privatwirtschaftlicher und transnationaler Einflußnahme. (Forschungen zu Lateinamerika Bd. 7). Saarbrücken, Fort Lauderdale 1986, S. 434, DM 49,--

Diese auf einem zweijährigen Forschungsaufenthalt 1980-1982 beruhende Dissertation faßt in einem umfangreichen Anhang wie auch in vielen Tabellen und Úbersichten lükkenlos die in Mexiko bestehenden Massenmedien zusammen, wie da sind Tagespresse, Rundfunk und Fernsehen sowie Nachrichtenagenturen. So werden etwa in der Úbersicht A-2 im Anhang die hauptstädtischen Tageszeitungen mit Titel, Untertitel, Gründungsdatum, Verlag, Gesellschaftsform, Angabe des Herausgebers und Hauptgeschäftsführers, Preis, Erscheinungsweise, Auflage und Verbindung zu Nachrichtenagenturen aufgeführt und auf S. $142 \mathrm{ff}$. näher untersucht. Die Intensität des hereingeholten Materials zeigt sich beispielsweise in der Wiedergabe der Monatsgehälter der Journalisten, S. 240, sowie der Anzeigenpreise von elf ausgewählten Tageszeitungen, S. 157. Akribisch werden die komplizierten Besitzverhältnisse bei den privaten Rundfunk- und Fernsehgesellschaften, allen voran Televisa, nachgezeichnet, S. $179 \mathrm{ff}$.

Von Interesse sind die vielfältigen Einflußversuche staatlicher Stellen auf die Massenmedien durch gezielte Lizenz- und Konzessionsvergaben, die Registrierung der Zeitungen und Zeitschriften als Voraussetzung für die Befreiung vom Porto, Zuteilung von Papier durch die PIPSA und plötzliche Schuldeneintreibung durch diese, Kreditvergabe durch die NAFINSA, Einfluß auf Journalistengewerkschaften, Inanspruchnahme von Sendezeiten, die die Rundfunkgesellschaften dem Staat zur Abgeltung von Steuerabgaben zur Verfügung stellen, Abdruck regierungsamtlicher Bulletins, Kanalisierung des Informationsflusses (so dargestellt im Falle Proceso im April 1982 durch López Portillo), Korrumpierung von Journalisten, gezielte Anzeigenplazierung und schließlich die reine Repressalie, allerdings kaum in der Hauptstadt, wohl aber in der Provinz, S. 308/9.

Auf S. 319 ff. befaßt sich B. mit dem in der Verfassung verankerten Recht auf Information (Art. 6). Ein derartiges staatlich gesichertes Recht wurde von der Privatwirtschaft als die Meinungsfreiheit potentiell beschränkend bekämpft. Die gutnachbarlichen Beziehungen zwischen dem staatlichen Fernsehkanal 13 und Televisa in der Amtsperiode López Portillo verhinderten einen stärkeren staatlichen Einfluß. Auch unter Präsident de la Madrid Hutardo änderte sich kaum etwas. Televisa war für die Úbertragung der Fußballweltmeisterschaft 1986 unentbehrlich.

Gerhard Scheffler 